\title{
NECESIDAD DE UN CAMBIO ESTRUCTURAL DEL SISTEMA TRIBUTARIO
}

\author{
THE NEED OF A STRUCTURAL CHANGE IN THE TRIBUTARY SYSTEM
}

\section{Julio C. Trujillo Meza}

[Recepción: Abril de 2009 / Conformidad: Mayo de 2009]

\section{RESUMEN}

El cambio del Sistema Tributario Nacional es hoy de necesidad imperativa partiendo del Presupuesto Público que contiene los ingresos de Tesoro Público, y por tanto, los ingresos tributarios de toda naturaleza, la necesidad de un cambio integral del Régimen Tributario permitiendo incluir otros tributos como el Impuesto al Patrimonio Personal y el Impuesto al Patrimonio Empresarial eliminando los tributos antitécnicos y ampliando la base de contribuyentes con una fuerte lucha contra la informalidad y la evasión tributaria, mediante una fiscalización por la Sunat se logre reducir la informalidad y la evasión tributaria y se evite la caída de la recaudación originada por estos hechos aunada a ello con la crisis financiera internacional.

Palabra clave: Reforma integral del sistema tributario, impuestos técnicos, eliminar los antitécnicos y ampliar la base de contribuyentes con una fiscalización por Sunat para incrementar la recaudación tributaria, tributación.

\begin{abstract}
The change of the Tributary (Tax) National System is today a need starting from the Public Budget that contains the income of Public Treasure and therefore the tributary $(\operatorname{tax})$ income of any nature. The need of an integral change of the Tributary (Tax) Regime allowing to include other taxes as the Tax to the Personal Patrimony and the Tax to the Managerial Patrimony eliminating the no-technical taxes and extending the contributors' base with a strong fight against the informality and the tributary (tax) evasion (this under the responsibility of Sunat) and by this avoiding the fall of collection generated originated by the financial international crisis.
\end{abstract}

Key word: Integral Reform of the Tributary (Tax) System, to create technical taxes, to eliminate the anti-technical and to extend the contributors' base". 


\section{INTRODUCCIÓN}

Los especialistas que observamos en el quehacer diario las diversas situaciones en la aplicación tributaria, consideramos que el sistema tributario nacional debe ser reestructurado integralmente, más aun cuando hoy se promueve la descentralización y/o regionalización a quienes se le debe dar un marco tributario para llegar al desarrollo del país, si la administración tributaria no reestructura su proceso de control y particularmente de proceso de fiscalización de los contribuyentes sean personas naturales o jurídicas y lograr una mayor recaudación tributaria.

La tributación es un instrumento de política económica que debe ser utilizado de la forma más racional y equitativa y ello se da a través del Presupuesto Público. Es necesario cambiar de modelo, de política económica y de política tributaria para eliminar la informalidad y la evasión tanto en la importación como en la exportación, así como en la aplicación de los tributos internos administrados por la Sunat.

Debería estudiarse un nuevo sistema tributario en el que se eliminen los tributos antitécnicos, se reestructuren los impuestos existentes y se implemente el impuesto al patrimonio personal y al patrimonio empresarial, tal como existe en España y otros países.

En ocasión anterior, en un artículo relacionado con las reflexiones sobre una reforma del sistema tributario nacional, señalamos la necesidad de su reestructuración integral con la participación de las instituciones involucradas, quienes deben facilitar el mecanismo apropiado para realizar este cambio necesario en las actuales circunstancias económicas del país.

El Gobierno, una vez más, ha estructurado su Presupuesto para el Ejercicio 2009. El monto asciende a S/. 72355497 884,00; en comparación la del Ejercicio 2008 fue de S/. 71049786794,00 . Se observa un incremento de S/. 1305711 090,00; que aparentemente demuestra que se sigue el mismo modelo económico sostenido con algunas normas o disposiciones que van a enfrentar a la actual crisis financiera internacional, pero que no plantean una solución al problema estructural económico financiero del país.

\section{PRESUPUESTO 2008 Y 2009}

Del presupuesto del 2009, podemos señalar que no hay un presupuesto sustancial y significativo que pueda inducir a que se priorizarán las inversiones de capital. Los ingresos al Tesoro Público por tributos representan el $65.1 \%$ y los egresos y gastos corrientes representan el $65.5 \%$, en otros términos, todos los tributos de diversa naturaleza recaudados por el Gobierno sirven para el pago de gastos corrientes que representan el gasto de instituciones públicas del Gobierno, dirigidas al pago de remuneraciones al personal de la Administración Pública, la adquisición de bienes y servicios fungibles, fundamentalmente.

Si bien hay una reducción en forma sustantiva en la amortización de la deuda de S/. 12566720828 destinados al pago de la deuda externa e interna en el 2008, para el 2009 se ha reducido a S/. 9231281 874, esto demuestra la disminución del pago de la deuda externa. No se incrementa mayormente los gastos de capital, por lo es necesario y urgente una racionalización severa en los gastos corrientes del Estado para que los tributos recaudados puedan ser orientados a las inversiones y gastos de capital. De este modo pueden construirse mayores postas médicas, hospitales y se destine a la infraestructura de carreteras, se incremente y mejore el servicio 
de la Policía Nacional del Perú y se reduzca sustantivamente el analfabetismo mediante un gran impulso sustancial a la educación.

\section{INGRESOS DE RECURSOS AL TESORO PÚBLICO}

Estos ingresos representan la recaudación que hace la Administración Tributaria de todos los tributos a nivel nacional, y como hemos podido observar en la referencia anterior el $65.1 \%$ es por ingresos al Tesoro Público; en otros términos, estos ingresos solventan sustantivamente el rubro de los egresos del Presupuesto Público y dada la importancia de la misma, el Gobierno debe prestar atención prioritaria al Sistema Tributario Nacional a fin de incrementar los mismos con una mayor recaudación.

La actual estructura del sistema tributario nacional no ha sufrido mayores cambios desde 1992, sólo se han producido algunas modificaciones de orden técnico y de orden formal. Pero el sistema, como Sistema, sigue siendo el de un "régimen tributario" que ha privilegiado la recaudación sin mejorar la misma, porque lo que se ha incrementado no son los contribuyentes inscritos y registrados, sino lo que se ha incrementado son aquellos contribuyentes informales y aquellos contribuyentes evasores de los impuestos, aunado a un sistema de fiscalización aparentemente bastante cuestionable, pues no se observa el mejoramiento del sistema tributario para un cumplimiento voluntario de las obligaciones tributarias. Tampoco se observa una fiscalización por la administración tributaria que tenga el objetivo de educar al contribuyente, detectar el incumplimiento de obligaciones formales y sustanciales y reflejar una producción real y efectiva como consecuencia del proceso de fiscalización. Este debe ser un sis- tema técnico de auditoría con una reglamentación adecuada y con un sistema que sustente el trabajo del fiscalizador para verificar el cumplimiento de las obligaciones tributarias y no estar con reiterados requerimientos para que sea el contador público de la empresa quien proporcione información que puede ser evaluada bien o mal por la administración tributaria en el domicilio del contribuyente.

\section{PERMANENCIA DEL RÉGIMEN TRIBUTARIO}

De acuerdo con indicado anteriormente, fluye la necesidad de un cambio estructural de régimen tributario. Ello implica reconsiderar el modelo económico, la política económica y la política fiscal, instrumentos que sirven para determinar el grado de renta que puede proporcionar el Estado a los contribuyentes para que puedan tener mayor disponibilidad y pueda incrementarse como una inyección económica suficiente; el grado de patrimonios igualmente que debe proporcionar el Estado a los contribuyentes; $y$, el incentivo a los consumos proporcionándole mayor disponibilidad económica al contribuyente con un aumento de sueldos y salarios, la liberación de la CTS y la exoneración de las gratificaciones, además, tributos que debidamente regulados deben ser suficientes para incrementar el presupuesto nacional y poder cumplir con los objetivos de las necesidades públicas para las cuales el Estado debe trabajar.

En la actualidad, nuestro régimen tributario desde el año 1992 en la práctica está distorsionado desde el punto de vista técnico y científico. Los tributos son los mismos, con excepción de la eliminación de los impuestos antitécnicos como fueron el Impuesto Mínimo a la Renta, el Impuesto Extraordinario a los Activos, el Anticipo Adicional de Renta, 
el Impuesto Extraordinario de Solidaridad. Sin embargo, bajo esa línea, el Estado, en un proceso de ilusión financiera o tributaria, ha mantenido el "Impuesto Temporal a los Activos Netos" creado el año 2004 por un periodo temporal y lo ha hecho permanente. Es un tributo antitécnico, en todo caso, debiera estudiarse la modificación de los sistemas de pagos a cuenta a la renta y eliminar definitivamente el llamado "Impuesto Temporal a los Activos Netos". Igualmente, el ITF es un impuesto negativo y de mínima recaudación pero que distorsiona el Sistema Tributario.

No hay cambio del sistema tributario porque no hay cambio de modelo económico, política económica, ni política fiscal y aquí nos preguntamos idebe seguirse con este régimen tributario o es que es momento que el Gobierno cambie la estructura del Estado y por tanto cambie el Sistema Tributario Nacional propiciando, si fuera el caso, una nueva Constitución Política o en su caso la modificación de la actual Constitución?

\section{NUEVO ORDENAMIENTO TRIBUTARIO}

Creemos que es urgente que se plantee la necesidad de un nuevo ordenamiento tributario con la participación de las instituciones involucradas ya señaladas. Este nuevo ordenamiento debe implicar la revisión estructural de los tributos existentes y la necesidad de implantar el impuesto al patrimonio de las personas naturales, así como el impuesto al patrimonio empresarial técnicamente y conforme existe y adecuándolo a los sistemas existentes de dichos impuestos en EspañaDebe darse prioridad al Sistema Tributario para las pequeñas y medianas empresas regulando un periodo de crecimiento para poder pasarlas al régimen general en su desarrollo normal, siendo fundamental cumplir la base tributaria con un estudio objetivo de la actual situación tributaria y sobre todo que la Administración Tributaria realice esa tarea necesaria y prioritaria para la obtención de mayores recursos recaudados.

\section{LA AMPLIACIÓN NECESARIA DE LA BASE DE CONTRIBUYENTES}

El Estado a través de sus instituciones y en especial a través de la Administración Tributaria debe iniciar una lucha contra la evasión tributaria en todas sus formas, con el objeto de incrementar la recaudación fiscal y para ello es necesario abordar el problema esencial de la política fiscal, que es la ampliación de la base tributaria.

El Estado no puede seguir con la política tributaria de las retenciones, percepciones, detracciones que significan una modalidad de pagos a cuenta, tampoco de mantener los tributos antitécnicos del Impuesto Temporal a los Activos Netos (ITAN), ni del Impuesto a las Transacciones Financieras (ITF), de recaudación mínima y hoy pretender gravar las transacciones comerciales con tarjetas de crédito y debito. Si bien estas medidas son efectistas, el sacrificio es mantener un régimen tributario, no obstante las propuestas y desacuerdos de las instituciones gremiales, profesionales y de otras instituciones.

Considero que la Administración Tributaria, al no tener un objetivo claro, propone mecanismos y formas que no contribuyen a combatir a la informalidad, a la evasión en las importaciones y exportaciones; así como en la aplicación de los tributos internos por la Sunat debido a la falta de una adecuada programación y aplicación en los procesos de control sobre las obligaciones tributarias sustanciales y formales, particularmente a la 
falta de un proceso de fiscalización o auditoría tributaria con transparencia y objetividad técnica.

\section{LA RECAUDACIÓN TRIBUTARIA Y EL SISTEMA TRIBUTARIO}

Es importante tomar la última información sobre la recaudación tributaria que justifica una atención preferente al Sistema Tributario.

El Gobierno ha declarado que los ingresos tributarios alcanzó a S/. 5,846 millones por el mes de abril del 2009, lo que representa una caída de $17.8 \%$, respecto al mes de marzo, además del efecto de la crisis financiera internacional y si se excluye las contribuciones sociales que representa la suma de $\mathrm{S} /$. 5,329 millones, la caída real sería de $13.3 \%$. Los tributos aduaneros registran S/. 1,129 millones representando una disminución en términos reales del $27 \%$. La recaudación del Impuesto a la Renta fue de S/.3,144 millones en el mes de abril, es decir, una disminución real del $21 \%$ respecto al mes anterior. La caída principal fue del Impuesto a la Renta de Tercera Categoría, la misma que fue de 703 millones con una caída real del $46.4 \%$ frente a marzo del 2008 explicada por la disminución de los pagos a cuenta mensuales de las empresas mineras. La recaudación del IGV registró apenas S/. 2,307 millones en abril, revelando una disminución real del 13.5\% respecto al mes de abril del año anterior.

Todo ello nos lleva a sostener la necesidad de reformular el Sistema Tributario integral. No es justo que los contribuyentes formales y honestos sean quienes cumplan sus obligaciones tributarias puntualmente mientras que los informales, los evasores, aquellos que están fuera de la base de contribuyentes que pagan impuntualmente sus impuestos, están en la periferia como contribuyentes potenciales eternamente.

\section{CONCLUSIONES}

El Sistema Tributario Nacional debe ser reestructurado integralmente en una decisión política del Gobierno y con la participación de las instituciones técnicas y profesionales.

Es necesario y oportuno brindarle a las regiones el marco tributario sobre el cual deben actuar para un desarrollo integral del país, los aportes o asignaciones del Poder Central deben ser fiscalizados.

El Presupuesto Público para el ejercicio 2009 es similar al 2008, con un ligero incremento, mostrando con ello que no hay una voluntad política del Gobierno para destinar mayores presupuestos a las inversiones de capital y reducir los gastos corrientes mediante una adecuada planificación.

Los ingresos de los recursos originados por los tributos en el presupuesto general de la República del 2009, están cubriendo los gastos corrientes y no hay una planificación en el ámbito de la Administración Tributaria para incrementar dichos ingresos mediante una efectiva fiscalización a los contribuyentes informales y a los evasores de impuestos en todos los ámbitos.

El Régimen Tributario sigue vigente desde el año 1992, si bien ha sufrido algunas modificaciones de orden técnico y formal, no ha cambiado en su estructura y se han eliminado tributos antitécnicos que violaban los principios constitucionales consagrados en el Art. $74^{\circ}$ de la Constitución Política del Estado; sin embargo aún se mantienen los tributos del ITAN y del ITF, que son de mínima recaudación y perjudican una mejor circulación económica y un perfeccionante del sistema. 
Es necesario propiciar un nuevo ordenamiento del Sistema Tributario tomando en cuenta la decisión política del Gobierno de hacer público el modelo económico, la política económica y la política fiscal, con la creación de tributos como el impuesto al patrimonio personal y el patrimonio empresarial, existentes en España y que existieron en el Perú, derogados con la creación del Impuesto mínimo a la Renta, propiciando tributos técnicos que tengan en cuenta la capacidad contributiva.

Debe ampliarse la base de contribuyentes con la inclusión de un considerable número de informales y de los evasores; tanto de la importación y exportación; como en la administración de los tributos internos para lograr un incremento en la recaudación. La recaudación se ha reducido y una adecuada fiscalización por la Sunat puede lograr el incremento en la recaudación.

\section{REFERENCIAS BIBLIOGRÁFICAS}

1. Constitución Política del Perú (1993)

2. Leyes del Presupuesto Público de los años 2008, Ley No 29142 y 2009 Ley No 29289.

3. Menéndez Moreno, Alejandro. (2000). Derecho Financiero y Tributario, España: Editorial Lex Nova.

4. Dino Jarach (1970). Curso Superior de Derecho Tributario, Argentina: Liceo Profesional Cima.

5. Ley del Impuesto a la Renta, Decreto Legislativo No 774.

6. Diario Gestión del 07 de mayo del 2009. 